\title{
Validation of the Male Osteoporosis Risk Estimation Score (MORES) in a Primary Care Setting
}

\author{
Alvah R. Cass, MD, SM, and Angela J. Shepherd, MD
}

Background: Primary care physicians are positioned to promote early recognition and treatment of men at risk for osteoporosis-related fractures; however, efficient screening strategies are needed. This study was designed to validate the Male Osteoporosis Risk Estimation Score (MORES) for identifying men at increased risk of osteoporosis.

Methods: This was a blinded analysis of the MORES, administered prospectively in a cross-sectional sample of men aged 60 years or older. Participants completed a research questionnaire at an outpatient visit and had a dual-energy X-ray absorptiometry (DXA) scan to assess bone density. Sensitivity, specificity, and area under-the-curve (AUC) were estimated for the MORES. Effectiveness was assessed by the number needed-to-screen (NNS) to prevent one additional major osteoporotic fracture.

Results: A total of 346 men completed the study. The mean age was $70.2 \pm 6.9$ years; $76 \%$ were nonHispanic white. Fifteen men (4.3\%) had osteoporosis of the hip. The operating characteristics were sensitivity 0.80 (95\% confidence interval [CI], 0.52-0.96); specificity 0.70 (95\% CI, 0.64-0.74), and AUC of 0.82 (95\% CI, 0.71-0.92). Screening with the MORES yielded a NNS to prevent one additional major osteoporotic fracture over 10 years with 259 (95\% CI, 192-449) compared to 636 for universal screening with a DXA.

Conclusion: This study validated the MORES as an effective and efficient approach to identifying men at increased risk of osteoporosis who may benefit from a diagnostic DXA scan. ( $\mathrm{J}$ Am Board Fam Med 2013;26:436-444.)

Keywords: Decision Making, Men's Health, Osteoporosis, Prevention, Primary Health Care, Screening

Physicians rarely screen men for osteoporosis, even men at high risk because of long-term glucocorticoid use or prior fragility fractures. ${ }^{1-7}$ Because low bone mineral density (BMD) is the single best predictor of future fragility fractures, ${ }^{8-10}$ identifying men at increased risk for osteoporosis who should undergo a dual-energy X-ray absorptiometry (DXA) scan may be worthwhile.

Osteoporotic fractures increase in men after 65 years of age,${ }^{11}$ an age group that is predicted to nearly

This article was externally peer reviewed.

Submitted 11 July 2012; revised 7 March 2013; accepted 11 March 2013.

From the Department of Family Medicine, The University of Texas Medical Branch, Galveston.

Funding: This research was supported by a grant from the Agency for Healthcare Research \& Quality (1R03HS017732-01) and funded a portion of the salary of ARC.

Conflict of interest: none declared.

Corresponding author: Alvah R. Cass, MD, SM, Department of Family Medicine, The University of Texas Medical Branch, 301 University Blvd., Galveston, TX 77555-1123 (E-mail: acass@utmb.edu). double in the United States by 2030. ${ }^{12}$ Osteoporotic fractures are associated with considerable morbidity and mortality: hip fractures account for the third-highest hospital bed occupancy among men. Only chronic obstructive pulmonary disease (COPD) and myocardial infarction account for more hospital days. ${ }^{13}$ Although osteoporosis is less common in men compared with women, in-hospital and 1-year mortality rates following a fracture are higher for men. ${ }^{14-18}$

Once osteoporosis is diagnosed, effective treatments aimed at fracture prevention are available. In women, treatment of osteoporosis with bisphosphonates reduces primary hip fractures by $40 \%$ to $50 \% .{ }^{19-23}$ Studies of the efficacy of bisphosphonate therapy for osteoporosis in men are not as robust as those in women; however, several research groups have concluded that the benefits of therapy in men, especially with respect to primary and secondary prevention of vertebral fractures, are similar to those in women. ${ }^{24-27}$ In men, results of treatment 
studies with bisphosphonates regarding nonvertebral fractures are inconsistent and may reflect the small number of men in these studies. ${ }^{28-32}$

Guidelines for osteoporosis screening of men are not uniform. In 2011, the US Preventive Services Task Force issued an I-statement and concluded that, "the current evidence is insufficient to assess the balance of benefits and harms of screening for osteoporosis in men." 33 Canadian guidelines promote universal screening with DXA in men $\geq 65$ years old. ${ }^{34}$ The National Osteoporosis Foundation $^{35}$ and American College of Preventive Medicine $^{36}$ recommend universal DXA screening of men $\geq 70$ years old. In contrast to "hard rules," the American College of Physicians ${ }^{37}$ recommends individualized screening decisions based on risk but offers no specific algorithms.

Several screening instruments have been developed and validated in women; however, these instruments are unlikely to be applicable in men. For example, several incorporate estrogen use, which is obviously not applicable to men. All use age, but the age-related risks are likely to differ between the sexes because of differences in age-related changes in bone density between men and women. After peak bone mass, men demonstrate a gradual decline in BMD over time, whereas women experience an accelerated loss of BMD following menopause. ${ }^{38}$ All algorithms use weight, but weight-related risks are also likely to differ between men and women because of differences in body habitus. Therefore, developing and validating an instrument for men seems prudent.

The Osteoporosis Self-Assessment Tool (OST) $)^{39}$ was originally developed for women but has been adapted for men ${ }^{40}$ and validated in the Osteoporotic Fractures in Men (MrOS) study; however, the more complex calculations and lack of a clearly defined cutoff value limit its clinical utility. ${ }^{41}$ Two tools have been developed and validated specifically for men: the Male Osteoporosis Screening Tool $(\text { MOST) })^{42}$ and the Male Osteoporosis Risk Estimation Score (MORES). ${ }^{43}$ The MOST was developed and internally validated in a cohort of Chinese men in Hong Kong (area under the curve [AUC] of 0.84 in the validation cohort). ${ }^{42}$ The MOST combines body weight and the quantitative ultrasound index obtained from a heel ultrasound to predict men at risk for osteoporosis and was subsequently validated in the MrOS cohort (AUC of 0.80 for Caucasian men and 0.83 for Chinese men). ${ }^{41}$ In the
MrOS study, the MOST was superior to the OST, which had a statistically significant lower AUC compared with the MOST (AUC of 0.71 for Caucasian men and 0.76 for Chinese men). The major limitation of the MOST is the reliance on a heel ultrasound, which is not readily available in most primary care practices and increases costs associated with screening.

The MORES, the primary focus of this study, was developed and validated in $2995 \mathrm{men}, \geq 50$ years old and representative of the general US population, enrolled in the National Health and Nutrition Examination Survey (NHANES) III. ${ }^{43}$ Using a weighted scale that includes age, weight, and history of COPD, the MORES identifies men at higher risk of osteoporosis who should undergo a diagnostic DXA scan (AUC, 0.83). The tool is easily incorporated into a clinical encounter and takes less than a minute to administer and score.

The development and evaluation of clinical decision rules are subject to methodological standards ${ }^{44}$ and progress through several defined stages ${ }^{45}$ during the process. This study describes the next critical step in the validation and evaluation of the MORES, namely prospective validation in an appropriate clinical setting. The purpose of this study is to validate the MORES in a primary care clinic population as a point-of-care decision tool to identify men at risk for osteoporosis and estimate the number needed-to-screen (NNS) to prevent one additional hip or major osteoporotic fracture over 10 years. The NHANES III cohort used to develop and internally validate the MORES was representative of the general US population at the time (1988 to 1994). Validation in a more current population is important because of variation in clinical characteristics over time and differences between the general population and patients attending primary care practices, who are likely to be less healthy. These potential differences may have unpredictable effects on the performance of a clinical prediction rule such as the MORES.

\section{Methods \\ Study Design}

This was a cross-sectional study of men who attended primary care outpatient clinics for usual care; its aim was to validate use of the MORES as a clinical decision tool to identify men at increased 
risk of osteoporosis. We enrolled men from November 12, 2008, through November 14, 2011. All participants provided written, informed consent. The Office of Research Subject Protections Institutional Review Board approved this study.

\section{Setting}

Participants came from university-based primary care outpatient clinics of the university's department of family medicine and the divisions of general internal medicine and geriatric medicine of the department of internal medicine.

\section{Subjects}

Men $\geq 60$ years old were invited to take part in the study. Men were excluded if they had a prior diagnosis of osteoporosis or bone diseases such as Paget disease; were taking bone density conservation agents such as bisphosphonates, calcitonin, or teriparatide; or had a history of bilateral hip replacement surgery. Men also were excluded if they exceeded the weight limit $(300 \mathrm{lb})$ of the DXA scanner.

\section{Procedure}

A research assistant interviewed participants and assisted with the completion of an investigatordesigned questionnaire that included demographic data, medical history, and the questions contained in the MORES.

After completing the research questionnaire, all participants were asked to have a DXA scan to measure BMD. The DXA scan served as the criterion to classify men as having osteoporosis. For this study, we extended the World Health Organization's definition of osteoporosis ${ }^{46}$ to include not only a $T$-score $\leq-2.5$ for the femoral neck but also a $\mathrm{T}$-score $\leq-2.5$ for the total hip because each is equally predictive of future fractures. ${ }^{47}$ The NHANES III cohort of non-Hispanic white women, 20 to 29 years old, served as the reference group. $^{48,49}$ DXA scans were performed on a Hologic QDR 4500A (Hologic, Inc., Bedford, MA) and a GE Lunar iDXA (GE Healthcare Global Diagnostic Imaging, Pewaukee, WI) scanner. The same technician completed all scans. Standardized conversion formulas furnished by GE Health Care were used to transform all measurements into comparable units (GE Healthcare, personal communication, 2010).
Table 1. Scoring Algorithm for the Male Osteoporosis Risk Estimation Score (MORES)

\begin{tabular}{ll}
\hline Risk Factor & $\begin{array}{c}\text { Point System for Scoring } \\
\text { the MORES* }\end{array}$ \\
\hline $\begin{array}{l}\text { Age (years) } \\
\leq 55 \text { (Ref) }\end{array}$ & 0 \\
$56-74$ & 3 \\
$\geq 75$ & 4 \\
Weight (kg) & \\
$\leq 70$ & 6 \\
$71-80$ & 4 \\
$>80$ (Ref) & 0 \\
Chronic obstructive pulmonary & 3 \\
$\quad$ disease & \\
\hline
\end{tabular}

*Screening threshold is $\geq 6$ points.

Ref, reference category.

Data were collected prospectively and analyzed in a blinded manner. The MORES was calculated independent of the BMD based on the scoring algorithm in Table 1. Likewise, the results of BMD were obtained independent of the results of the MORES.

\section{Instruments}

The MORES is a clinical risk stratification index developed in 2007 and internally validated in 2995 men $\geq 50$ years old from the NHANES III dataset. $^{43}$ A best-fitted logistic regression model used age, weight, and history of COPD to predict osteoporosis. Each factor retained in the model contributed a significant and independent effect to the risk of osteoporosis. The weights assigned to each factor were transformed from the regression coefficients to yield integer values indicative of the magnitude of effect on the risk of osteoporosis. A score of $\geq 6$ maximally discriminated between men at higher versus lower risk of osteoporosis and yielded a sensitivity of 0.93 , a specificity of 0.59 , an AUC of 0.83 , and a NNS to prevent one additional hip fracture over 10 years of 279. In a subsequent study, the MORES was validated for identifying men at increased risk for lumbar osteoporosis. ${ }^{50}$ Table 1 summarizes the weighted scoring algorithm.

\section{Power Analysis}

We estimated the prevalence of osteoporosis of the hip in men $\geq 60$ years old at $7.0 \%$. A sample of 350 men could then be expected to make available ap- 
proximately 25 cases of osteoporosis of the hip to validate the MORES.

With a sample size of 25 men with osteoporosis, a 2 -sided exact binomial test for a single proportion $(\alpha<0.05)$ would have at least $80 \%$ power to detect the difference between the null hypothesis of 0.50 and an alternative hypothesis as low as 0.77 for the sensitivity of the MORES. Calculations were made using nQuery Advisor 7.0. ${ }^{51}$

\section{Analysis}

We used a $2 \times 2$ contingency table to obtain the operating characteristics of the MORES, using a threshold of $\geq 6$ points as the positive criterion and osteoporosis of the hip as the outcome state. We obtained $95 \%$ confidence intervals [CIs] for the sensitivity, specificity, positive predictive value, and negative predictive value using an exact method based on the binomial distribution. We used the binomial test for a single proportion to determine whether the observed sensitivity differed significantly from 0.50 (the null hypothesis). Assuming a nonparametric distribution, we estimated the AUC for the MORES.

To estimate the clinical utility of the MORES, we conducted an impact analysis estimating the NNS to prevent one additional hip fracture and one additional major osteoporotic fracture over 10 years following the methods described by Nelson et al. ${ }^{52}$ We used the prevalence observed in the current study to estimate the prevalence of osteoporosis and the operating characteristics observed in the current study to estimate the sensitivity and specificity of the MORES. Ten-year fracture rates were derived from estimates afforded by the FRAX calculation tool. ${ }^{53,54}$ Additional assumptions for the impact analysis were taken from Nelson et $\mathrm{al}^{52}$ and included a $70 \%$ rate of compliance with treatment and 0.63 relative risk reduction for hip fracture with treatment. We varied the relative risk reduction with treatment for a major osteoporotic fracture as a weighted average from other published studies. $^{19,20}$

\section{Results}

We enrolled 386 men; however, 40 men did not report for the DXA scan after 3 requests and were dropped from the study. The final study population included the 346 men with an interpretable DXA scan. There were no significant differences be- tween the men with and without a DXA scan with regard to age, weight, race/ethnicity, education, marital status, or history of COPD. The average age of men completing the study was $70.2 \pm 7.0$ years. Of these men, $76.0 \%$ were non-Hispanic white, $11.8 \%$ were African American, 10.7\% were Hispanic, and $1.5 \%$ were Asian or other. The majority of men were high school graduates (87.9\%), and most were married or living with someone (70.9\%). Fifteen men (4.3\%) had osteoporosis of the hip based on the criteria described in the Methods section. See Table 2 for a detailed description of the study population.

The MORES correctly identified 12 of the 15 men with osteoporosis of the hip, yielding a sensitivity of 0.80 (95\% CI, $0.52-0.96 ; P=0.035$, 1-sample binomial test). The observed specificity for the MORES was 0.70 (95\% CI, 0.64-0.74). As a result, the $11 \%$ of men who screened positive with the MORES were nearly 3 times as likely to have osteoporosis compared with the baseline prevalence of $4.3 \%$. Men who screened negative with the MORES had only a $1 \%$ chance of having osteoporosis. The MORES demonstrated an excellent capacity to discriminate between men with and without osteoporosis of the hip based on an AUC of 0.82 (95\% CI, 0.71-0.92). ${ }^{55}$ Table 3 provides a detailed summary comparing the operating characteristics of the MORES derived from the current study with those obtained from the NHANES III cohort.

Table 4 summarizes the adjusted odds ratios for the MORES indicator variables derived from a logistic regression equation predicting the dependent variable, osteoporosis of the hip, from the dependent variables defined by age groups, weight groups, and history of COPD. The magnitude of the adjusted odds ratios are similar to the weights derived from the NHANES III cohort. The regression equation from the MORES predictor variables yielded a well-calibrated model for predicting osteoporosis in the study population (Hosmer-Lemeshow goodness of fit statistic, ${ }^{56} \chi_{d f=4}^{2}=3.339$; $P=0.503)$.

To estimate the potential clinical utility of the MORES, we conducted an impact analysis to estimate the number of men who would be referred for a diagnostic DXA scan to prevent one additional hip fracture or one additional major osteoporotic fracture. The NNS to prevent one additional hip fracture with treatment over 10 years was 654 (95\% 
Table 2. Validation of the Male Osteoporosis Risk Estimation Score (MORES): Demographic and Clinical Characteristics of the Primary Care Study Sample $(\mathrm{n}=346)$

\begin{tabular}{|c|c|}
\hline Variables & \\
\hline Age, years $($ mean $\pm \mathrm{SD})$ & $70.2 \pm 6.9$ \\
\hline Height, cm (mean $\pm \mathrm{SD})$ & $177.4 \pm 7.2$ \\
\hline Weight, $\mathrm{kg}($ mean $\pm \mathrm{SD})$ & $90.2 \pm 16.7$ \\
\hline Osteoporosis* & $15(4.3)$ \\
\hline Severe osteopenia $^{\dagger}$ & $19(5.5)$ \\
\hline \multicolumn{2}{|l|}{ Race/ethnicity } \\
\hline Non-Hispanic white & $263(76.0)$ \\
\hline African American & $41(11.8)$ \\
\hline Hispanic & $37(10.7)$ \\
\hline Other & $5(1.4)$ \\
\hline \multicolumn{2}{|l|}{ Education } \\
\hline Less than high school & $42(12.1)$ \\
\hline High school graduate & $70(20.2)$ \\
\hline College/college graduate & $172(49.7)$ \\
\hline Postgraduate & $62(17.9)$ \\
\hline \multicolumn{2}{|l|}{ Marital status } \\
\hline Married/living with someone & $245(70.9)$ \\
\hline Single/never married & $28(8.1)$ \\
\hline Divorced/separated & $42(12.1)$ \\
\hline Widowed & $31(9.0)$ \\
\hline Family history of parental hip fracture & $42(12.1)$ \\
\hline Previous fragility fracture & $6(1.7)$ \\
\hline History of rheumatoid arthritis & $7(2.0)$ \\
\hline $\begin{array}{l}\text { History of secondary cause of } \\
\text { osteoporosis }\end{array}$ & $31(9.0)$ \\
\hline Chronic obstructive pulmonary disease & $29(8.4)$ \\
\hline \multicolumn{2}{|l|}{ Alcohol use } \\
\hline Current use & $217(62.7)$ \\
\hline Heavy ( $\geq 3$ drinks per day) & $23(6.6)$ \\
\hline \multicolumn{2}{|l|}{ Tobacco use } \\
\hline Current smoker & $39(11.3)$ \\
\hline Former smoker & $201(58.1)$ \\
\hline Never smoked & $106(30.6)$ \\
\hline Glucocorticoid use & $7(2.0)$ \\
\hline
\end{tabular}

Values are $\mathrm{n}(\%)$ unless otherwise indicated.

${ }^{*}$ T-score $\leq-2.5$, femoral neck/total hip.

${ }^{\dagger}-2.5<\mathrm{T}$-score $\leq--2.0$, femoral neck/total hip.

CI, 485-1132) compared with 1604 for universal DXA screening. The NNS to prevent one additional major osteoporotic fracture over 10 years ranged from 245 to 276 , depending on the effectiveness of treatment in preventing major osteoporotic fractures. ${ }^{19,20}$ By comparison, the NNS for universal screening to prevent one additional major osteoporotic fracture ranged from 600 to 675 . Table 5 provides the details of the impact analyses.
Table 3. Comparison of Operating Characteristics of the Male Osteoporosis Risk Estimation Score in the National Health and Nutrition Examination Survey (NHANES) III Development Study ${ }^{43}$ and the Current Validation Study

\begin{tabular}{lcc}
\hline & $\begin{array}{c}\text { NHANES III } \\
(\mathrm{n}=2995)\end{array}$ & $\begin{array}{c}\text { Current Study } \\
(\mathrm{n}=346)\end{array}$ \\
\hline $\begin{array}{l}\text { Prevalence of osteoporosis } \\
(\%)\end{array}$ & 4.8 & 4.3 \\
$\begin{array}{l}\text { Sensitivity } \\
\text { Specificity }\end{array}$ & $0.93(0.88-0.97)$ & $0.80(0.52-0.96)$ \\
Positive predictive value & $0.59(0.57-0.61)$ & $0.70(0.64-0.74)$ \\
Negative predictive value & $0.99(0.09-0.12)$ & $0.11(0.06-0.18)$ \\
Area under the curve & $0.83(0.81-0.86)$ & $0.99(0.96-1.00)$ \\
\end{tabular}

95\% Confidence intervals are set in parentheses.

\section{Discussion}

The MORES is a simple risk stratification tool that can be used at the point of care and requires $<1$ minute to administer and score. Men with a score of $\geq 6$ points are considered at risk for osteoporosis and should be referred for a diagnostic DXA scan. In our clinical sample, we found a sensitivity of 0.80 and a specificity of 0.70 for the MORES. Although the estimated sensitivity and specificity varied from the NHANES III cohort, the AUC was similar (0.82 vs. 0.83$)$, which indicates excellent discrimination $^{55}$ and validates the MORES as a clinical risk stratification tool that can be used in a clinical population to identify men at increased risk for

Table 4. Distribution of the Male Osteoporosis Risk Estimation Score Risk Factors in Men With and Without Osteoporosis of the Hip

\begin{tabular}{|c|c|c|c|}
\hline Risk Factor & $\begin{array}{l}\text { Osteoporosis } \\
(\mathrm{n}=15)\end{array}$ & $\begin{array}{c}\text { No } \\
\text { Osteoporosis } \\
(\mathrm{n}=331)\end{array}$ & $\begin{array}{c}\text { Adjusted Odds } \\
\text { Ratio } \\
(95 \% \mathrm{CI})\end{array}$ \\
\hline \multicolumn{4}{|l|}{ Age } \\
\hline$\leq 55$ & - & - & - \\
\hline $56-74$ & 5 & 253 & Reference \\
\hline$\geq 75$ & 10 & 78 & $6.4(2.0-20.0)$ \\
\hline \multicolumn{4}{|l|}{ Weight (kg) } \\
\hline$\leq 70$ & 4 & 29 & $8.6(1.9-38.2)$ \\
\hline $71-80$ & 7 & 55 & $6.7(1.8-24.7)$ \\
\hline$>80$ & 4 & 247 & Reference \\
\hline \multicolumn{4}{|c|}{$\begin{array}{l}\text { Chronic obstructive } \\
\text { pulmonary } \\
\text { disease }\end{array}$} \\
\hline Yes & 3 & 26 & $3.0(0.7-13.0)$ \\
\hline No & 12 & 305 & Reference \\
\hline
\end{tabular}


Table 5. Impact Analysis of the Male Osteoporosis Risk Estimation Score (MORES)*: Simulated Screening for Osteoporosis in 10,000 Men, 60 Years of Age and 01der, and 10-year Fracture Outcomes

\begin{tabular}{|c|c|c|c|c|c|c|}
\hline & \multicolumn{2}{|c|}{$\begin{array}{c}\text { NHANES III } \\
\text { Development Cohort }{ }^{43} \\
(\mathrm{n}=2995)\end{array}$} & \multicolumn{4}{|c|}{$\begin{array}{l}\text { Clinical Validation Cohort } \\
\qquad(\mathrm{n}=346)\end{array}$} \\
\hline & \multicolumn{2}{|c|}{ Hip Fracture } & \multicolumn{2}{|c|}{ Hip Fracture } & \multicolumn{2}{|c|}{$\begin{array}{l}\text { Major Osteoporotic } \\
\text { Fracture }\end{array}$} \\
\hline & MORES & Universal & MORES & Universal & MORES & Universal \\
\hline Population (n) & 10,000 & 10,000 & 10,000 & 10,000 & 10,000 & 10,000 \\
\hline Sensitivity (MORES) & 0.930 & - & 0.800 & - & 0.800 & - \\
\hline Specificity (MORES) & 0.590 & - & 0.695 & - & 0.695 & - \\
\hline Fracture risk ${ }^{\dagger}$ & 0.135 & 0.135 & 0.056 & 0.056 & 0.123 & 0.123 \\
\hline Osteoporosis prevalence & 0.048 & 0.048 & 0.043 & 0.043 & 0.043 & 0.043 \\
\hline Relative risk of fracture with treatment ${ }^{\ddagger}$ & 0.630 & 0.630 & 0.630 & 0.630 & 0.575 & 0.575 \\
\hline Adherence to treatment ${ }^{\S}$ & 0.700 & 0.700 & 0.700 & 0.700 & 0.700 & 0.700 \\
\hline Predicted cases & 480 & 480 & 430 & 430 & 430 & 430 \\
\hline True positive & 446 & 480 & 344 & 430 & 344 & 430 \\
\hline False negative & 34 & - & 86 & - & 86 & - \\
\hline True negative & 5,617 & 9,520 & 6,651 & 9,570 & 6,651 & 9,570 \\
\hline False positive & 3,903 & - & 2,919 & - & 2,919 & - \\
\hline $\begin{array}{l}\text { Referred for DXA (true positive }+ \text { false } \\
\text { positive) }\end{array}$ & 4,350 & 10,000 & 3,263 & 10,000 & 3,263 & 10,000 \\
\hline \multicolumn{7}{|l|}{ Predicted hip fractures: MORES/DXA } \\
\hline True positive & 44.66 & 48.02 & 14.27 & 17.84 & 29.75 & 37.19 \\
\hline False negative & 4.54 & 0.00 & 4.82 & 0.00 & 10.59 & 0.00 \\
\hline Total & 49.19 & 48.02 & 19.09 & 17.84 & 40.33 & 37.19 \\
\hline Unscreened (no DXA) & 64.80 & 64.80 & 24.08 & 24.08 & 52.93 & 52.93 \\
\hline Number needed-to-screen (95\% CI) & $279(257-306)$ & $596(-)$ & $654(485-1132)$ & $1,604(-)$ & $259(192-449)$ & $636(-)$ \\
\hline
\end{tabular}

*Formulas used in the calculation were adapted from Nelson et al. ${ }^{52}$ and are available upon request.

${ }^{\dagger}$ Fracture risks for the NHANES III cohort were obtained from Kanis et al. ${ }^{58}$ Fracture risks for the current study were obtained from FRAX for both hip and major osteoporotic fractures and reflect the characteristics of the study population. ${ }^{54}$

${ }^{\ddagger}$ Risk reduction estimates are supported by clinical trials, and the estimates for hip fractures are those used by Nelson et al. ${ }^{52}$ The point estimate for the relative risk reduction for major osteoporotic fractures is a weighted average from published reports. ${ }^{19,20}$

${ }^{\S}$ Compliance with treatment estimates are from Nelson et al..$^{52}$

DXA, dual-energy X-ray absorptiometry; NHANES, National Health and Nutrition Examination Survey.

osteoporosis. Using the 2-step approach (positive MORES followed by DXA), $33 \%$ of men $\geq 60$ years old would be referred for a DXA scan and $80 \%$ of men with osteoporosis would be identified correctly.

The slightly lower prevalence of osteoporosis in the clinical setting compared with the prevalence in the NHANES III data set was unexpected. In fact, a higher prevalence was expected because of the older age of the clinic participants. The lower prevalence may have been affected by 2 factors. The first is related to the debate over which reference standard and anatomic site should be used to diagnosis osteoporosis, which has taken place in the decade after publication of the NHANES III data. ${ }^{48}$ The development and internal validation of the MORES used T-scores based on sex-specific and race/ethnicity-based reference groups for the total hip. In contrast, the World Health Organization $^{46}$ recommends that osteoporosis should be determined by comparing BMD measurements of the femoral neck for males and females of all races/ ethnicities to 20 to 29 year-old white female norms from the NHANES III. For example, changing the critical value to define osteoporosis from a BMD of $\leq 0.681 \mathrm{~g} / \mathrm{cm}^{2}$ for the total hip, based on 20 to 29 year-old white men, to a BMD of $\leq 0.558 \mathrm{~g} / \mathrm{cm}^{2}$ for the femoral neck, based on 20 to 29 year-old white women, results in fewer men being classified as having osteoporosis. ${ }^{48}$

The second factor that may explain a lower prevalence is a potential study bias toward more robust older men. This study involved a sample of men from one geographic area along the Gulf coast of 
Texas, with Galveston Island as the major population center. On September 13, 2008, 2 months before the study began, Galveston Island sustained a direct hit from Hurricane Ike and the devastation of a 22 -ft storm surge ${ }^{57}$ Before landfall, a mandatory evacuation was ordered, which included all patients in skilled nursing facilities, nursing homes, and hospitals. For months afterward, access to medical facilities was limited, and many potentially eligible men (especially elderly men and those with frailties) were displaced. This may have biased the study group toward men who were healthy enough to return during hurricane recovery and restoration efforts and who may have been less likely to have osteoporosis.

The lower sensitivity observed for the MORES in the current study, compared with the NHANES III cohort, is a concern; however, the CIs for the 2 estimates overlap. The sensitivity found in this study may be more a function of the limited number of men with osteoporosis than a limitation of the MORES as risk stratification instrument. The estimated AUC in this study (0.81) is essentially identical to that seen in the NHANES III cohort (0.83) and, in absolute terms, confirms that the MORES is a robust instrument that can be used to differentiate men at higher risk of osteoporosis from those at lower risk.

The impact analysis demonstrates that the MORES provides an efficient approach to screening men for osteoporosis. The overall NNS to prevent one additional hip fracture over 10 years (654) was higher than that in the NHANES III cohort (279). The difference is mostly due to the lower 10-year risk of fracture (0.056) used in the current study, which was derived from the FRAX estimates for our population, compared with the 10 -year risk of fracture (0.135) obtained from Kanis et $\mathrm{al}^{58}$ used in the initial study. If the hip fracture rates estimated from FRAX are used to compare the current study to the NHANES III study, then the difference in the NNS is negligible (654 vs. 672), despite the lower sensitivity of the MORES seen in the current study. More importantly, in this study, the NNS to prevent any major osteoporotic fracture, based on FRAX estimates, is much lower (298) than for hip fracture alone.

Our study had limitations. The study was conducted in one geographical area among a relatively small number of men, which limits generalizability. However, this study does add to the evidence that the MORES is a valid instrument. ${ }^{43,50}$ The small sample size precluded any stratified analyses by age, race/ethnicity, or anatomic site of osteoporosis. Studies of larger samples from other geographic regions are needed to assess further the validity of the MORES and evaluate the operating characteristics of the MORES stratified by age and race/ ethnicity.

\section{Conclusion}

We developed the MORES to be used by primary care physicians during an ambulatory visit to identify men at increased risk for osteoporosis, the foremost modifiable risk factor for future major fractures. The results of this study provide further evidence that the MORES is a valid and efficient tool that can be used to identify men at increased risk for osteoporosis in a clinical setting. On the basis of the results from this clinical study, $33 \%$ of men screened positive with the MORES and would be referred for a diagnostic DXA scan. At least $80 \%$ of men with osteoporosis would be identified correctly. While the evidence that treatment of osteoporosis reduces future fracture in men is less well established than in women, we believe the early evidence supports treating men with osteoporosis. ${ }^{24-32}$ For primary care physicians, identifying and treating men with osteoporosis may be an important step in the prevention of future fractures.

\section{References}

1. Elliott ME, Farrah RM, Binklye NC, Carnes ML, Gudmundsson A. Management of glucocorticoidinduced osteoporosis in male veterans. Ann Pharmacother 2000;34:1380-4.

2. Kiebzak GM, Beinart GA, Perser K, Ambrose CG, Siff SJ, Heggeness MH. Undertreatment of osteoporosis in men with hip fracture. Arch Intern Med 2002;162:2217-22.

3. Solomon DH, Katz JN, Jacobs JP, La Tourette AM, Coblyn J. Management of glucocorticoid-induced osteoporosis in patients with rheumatoid arthritis. Arthritis Rheum. 2002;46:3136-42.

4. Curtis JR, Westfall AO, Allison JJ, et al. Longitudinal patterns in the prevention of osteoporosis in glucocorticoid-treated patients. Arthritis Rheum 2005;52:2485-94.

5. Feldstein AC, Nicholson GC, Orwoll E, et al. The near absence of osteoporosis treatment in older men with fractures. Osteoporos Int. 2005;16:953-62.

6. Cruse LM, Valeriano J, Vasey FB, Carter JD. Prevalence of evaluation and treatment of glucocorticoid- 
induced osteoporosis in men. J Clin Rheumatol. 2006;12:221-5.

7. Shepherd AJ, Cass AR, Ray LA, Tan A, Wilkinson GS. Treatment for older men with fractures. Osteoporos Int 2012;23:1041-51.

8. Kanis JA, Melton III LJ, Christiansen C, Johnston CC Jr, Khaltaev N. The diagnosis of osteoporosis. J Bone Miner Res 1994;9:1137-41.

9. NIH Consensus Development Panel. Osteoporosis prevention, diagnosis and therapy. JAMA 2001;285: 785-95.

10. Lewis CE, Ewing SK, Taylor BC, et al. Predictors of non-spine fracture in elderly men: the MrOS study. J Bone Miner Res 2007;22:211-9.

11. Melton III LJ, Crowson CS, O'Fallon WM. Fracture incidence in Olmsted County, Minnesota: comparison of urban with rural rates and changes in urban rates over time. Osteoporos Int 1999;9:29-37.

12. Day JC. Population projections of the United States by age, sex, and Hispanic origin: 1995 to 2050, U.S. Bureau of the Census, Current Population Reports, Washington (DC): U.S. Government Printing Office, February 1996.

13. Kanis JA, McCloskey E. Evaluation of the risk of hip fracture. Bone 1996;18:S127-32.

14. Forsen L, Sogaard AJ, Meyer HE, Edna T, Kopjar B. Survival after hip fracture: short and long-term excess mortality according to age and gender. Osteoporos Int 1999;10:73-8.

15. Center JR, Nguyen TV, Schneider D, Sambrook $\mathrm{PN}$, Eisman J. Mortality after all major types of osteoporotic fracture in men and women: an observational study. Lancet 1999;353:878-82.

16. Haentjens P, Magaziner J, Colón-Emeric CS, et al. Meta-analysis: excess mortality after hip fracture among older men and women. Ann Intern Med 2010;152:380-90.

17. Kannegaard PN, van der mark S, Eiken P, Abrahamsen B. Excess mortality in men compared with women following a hip fracture: national analysis of comedications, comorbidity, and survival. Age Ageing 2010;39:203-9.

18. Panula J, Pihlajamäki H, Mattila VM, et al. Mortality and cause of death in hip fracture patients aged 65 or older: a population-based study. BMC Musculoskelet Disord 2011;12:105.

19. Black DM, Cummings SR, Karpf DB, et al. Randomised trial of effect of alendronate on risk of fracture in women with existing vertebral fractures. Lancet 1996;347:1535-41.

20. Harris ST, Watts NB, Genant HK, et al. Effects of risedronate treatment on vertebral and nonvertebral fractures in women with postmenopausal asteoporosis: a randomized controlled trial. JAMA 1999;282: 1344-52.

21. Black DM, Thompson DE, Bauer DC, et al. Fracture risk reduction with alendronate in women with osteoporosis: The Fracture Intervention Trial. J Clin Endocr Metab 2000;85:4118-24.

22. McClung MR, Geusens P, Miller PD, et al. Effect of risedronate on the risk of hip fracture in elderly women. N Engl J Med 2001;344:333-40.

23. Hodsman AB, Hanley DA, Robert J. Do bisphosphonates reduce the risk of osteoporotic fractures? An evaluation of the evidence to date. CMAJ 2002; 166:1426-30.

24. Orwoll ES. Assessing bone density in men. J Bone Miner Res 2000;15:1867-70.

25. Ho YV, Frauman AG, Thomson W, Seeman E. Effects of alendronate on bone density in men with primary and secondary osteoporosis. Osteoporos Int 2000;11:98-101.

26. Weber TJ, Drezner MK. Effect of alendronate on bone mineral density in male iodiopathic osteoporosis. Metab Clin Exper 2001;50:912-5.

27. Gonnelli S, Cepollaro C, Montagnani AM, et al. Alendronate treatment in men with primary osteoporosis: a three year longitudinal study. Calcif Tissue Int 2003;73:133-9.

28. Orwoll E, Ettinger M, Weiss S, et al. Alendronate for the treatment of osteoporosis in men. $\mathrm{N}$ Engl J Med 2000;343:604-10.

29. Ringe JD, Dorst A, Faber H, Ibach K. Alendronate treatment of established primary osteoporosis in men: 3-year results of a prospective, comparative, two-arm study. Rheumatol Int 2004;24:110-3.

30. Sato Y, Iwamoto J, Kanoko T, Satoh K. Risedronate sodium therapy for prevention of hip fracture in men 65 years or older after stroke. Arch Intern Med 2005; 165:1743-8.

31. Sawka AM, Papaioannou A, Adachi JD, Gafni A, Hanley DA, Thabane L. Does alendronate reduce the risk of fracture in men? A meta-analysis incorporating prior knowledge of anti-fracture efficacy in women. BMC Musculoskelet Disord. 2005;6:39.

32. Sato Y, Honda Y, Iwamoto J. Risedronate and ergocalciferol prevent hip fracture in elderly men with Parkinson disease. Neurology 2007;68:911-5.

33. U.S. Preventive Services Task Force. Screening for osteoporosis: U.S. Preventive Services Task Force recommendation statement. Ann Intern Med 2011; 154:356-64.

34. Papaioannou A, Morin S, Cheung AM, et al. 2010 Clinical practice guidelines for the diagnosis and management of osteoporosis in Canada: summary. CMAJ 2010;182:1864-73.

35. National Osteoporosis Foundation. Physician's guide to prevention and treatment of osteoporosis. Washington, DC: National Osteoporosis Foundation; 2003.

36. Lim LS, Hoeksema LJ, Sherin K; ACPM Prevention Practice Committee. Screening for osteoporosis in the adult U.S. population: ACPM position statement on preventive practice. Am J Prev Med 2009;36: $366-75$. 
37. Qaseem A, Snow V, Shekelle P, Hopkins R Jr, Forciea MA, Owens DK. Screening for osteoporosis in men: a clinical practice guideline from the American College of Physicians. Ann Intern Med 2008;148: 680-4.

38. Khosla S. Pathogenesis of age-related bone loss in humans. J Gerontol A Biol Sci Med Sci. 2012 Aug 24. [Epub ahead of print]

39. Koh LKH, Sedrine WB, Torralba TP, et al. A simple tool to identify Asian women at increased risk of osteoporosis. Osteoporos Int 2001;12:699-705.

40. Hochberg MC, Tracy JK, van der Klift M, Pols H. Validation of a risk index to identify men with an increased likelihood of osteoporosis. J Bone Miner Res 2002;17(Suppl 1):S231.

41. Lynn HS, Woo J, Leung PC, et al. An evaluation of osteoporosis screening tools for the osteoporotic fractures in men (MrOS) study. Osteoporos Int 2008;19:1087-92.

42. Lynn HS, Lau EMC, Wong SYS, Hong AWL. An osteoporosis screening tool for Chinese men. Osteoporos Int 2005;16:829-34.

43. Shepherd AJ, Cass AR, Carlson CA, Ray LA. Development and internal validation of the male osteoporosis risk estimation score. Ann Fam Med 2007;5: 540-6.

44. Bossuyt PM, Reitsma JB, Burns DE, et al. Towards complete and accurate reporting of studies of diagnostic accuracy: the STARD initiative. Fam Pract 2004;21:4-10.

45. Stiell IG, Wells GA. Methodologic standards for development of clinical decision rules in emergency medicine. Ann Emerg Med 1999;33:437-47.

46. World Health Organization. WHO Scientific Group on the assessment of osteoporosis at primary health care level. Paper presented at: Summary Meeting Report, May 5-7, 2004, Brussels, Belgium.

47. Stone KL, Seeley DG, Lui L-Y, et al. BMD at multiple sites and risk of fracture of multiple types: long-term results from the study of osteoporotic fractures. J Bone Miner Res 2003;18:1947-54.

48. Looker AC, Wahner HW, Dunn WL, et al. Updated data on proximal femur bone mineral levels of US adults. Osteoporos Int 1998;8:468-89.

49. Binkley N, Bilezikian JP, Kendler DL, et al. Official position of the International Society for Clinical Densitometry and executive summary of the 2005 Position Development Conference. J Clin Densitometry 2006;9:4-14.

50. Shepherd AJ, Cass AR, Carlson CA, Ray LA. Determining risk of vertebral osteoporosis in men: validation of the Male Osteoporosis Risk Estimation Score. J Am Board Fam Med 2010;23:186-94.

51. Elashoff JD. nQuery Advisor version 7.0. Boston: Statistical Solutions, Ltd.; 2007.

52. Nelson HD, Helfand M, Woolf SH, Allan J. Screening for postmenopausal osteoporosis: a review of the evidence for the US Preventive Services Task Force. Ann Intern Med 2002;137:529-41.

53. Kanis JA, Johnell O, Oden A, Johansson A, McCloskey E. FRAX and the assessment of fracture probablility in men and women from the UK. Osteoporos Int 2008;19:385-97.

54. World Health Organization Collaborating Centre for Metabolic Bone Diseases. Welcome to FRAX. Available from: http://www.shef.ac.uk/FRAX/index. aspx. Accessed January 24, 2012.

55. Hosmer DW, Lemeshow S. Applied logistic regression. 2nd ed. New York: John Wiley \& Sons; 2000.

56. Hosmer DW, Lemeshow S. A goodness-of-fit test for the multiple logistic regression model. Commun Stat Theory Methods 1980;9:1043-69.

57. Wikipedia. Effects of Hurricane Ike in Texas. 2012. Available from: http://en.wikipedia.org/w/index.php? title=Effects_of_Hurricane_Ike_in_Texas. Accessed February 10, 2012.

58. Kanis JA, Oden A, Johnell O, Jonsson B, De Laet C, Dawson A. The burden of osteoporotic fractures: a method for setting intervention thresholds. Osteoporos Int 2001;12:417-27. 